\title{
Preface: Special issue of research on chemical intermediates
}

\section{Masakazu Anpo ${ }^{1,2}$. Jinlong Zhang ${ }^{3}$}

Published online: 15 October 2019

(c) Springer Nature B.V. 2019

On March 6, 1869, Dmitri Ivanovich Mendeleev (Russian name: Дмитрий Иванович Менделеев) gave a presentation entitled "The Dependence between the Properties of the Atomic Weights of the Elements" at the Russian Chemical Society. In this presentation, he described and pointed out that the periodicity and relationship between the chemical properties of elements were found when these elements were arranged according to their atomic weight. He developed his periodic table consisting of all known elements and also predicted several unknown elements to complete and publish his table in a Russian journal. Since then, this periodic table has played an important role in understanding not only chemistry but also physics.

This year, 2019, is the 150th anniversary of the discovery of this useful framework for the elements, and with the support of Springer, we, the editors of Res. Chem. Intermed., have arranged this Special Issue to commemorate this momentous discovery. Almost all of the members of the Editorial Board of this journal have kindly contributed an article to this Special Issue, making it one of the most interesting and instructive. It consists of original articles and review articles including many on the different elements in the periodic table.

We hope the excellent work carried out in this Special Issue will play an important role in the development of ecologically clean and safe, sustainable and energyefficient chemical sciences and technologies, one of the greatest challenges facing researchers today.

We would like to thank the late Prof. Michel Che with whom we had several exchanges and discussions regarding this project since December, 2018. As one of

Masakazu Anpo

anpo@chem.osakafu-u.ac.jp

Jinlong Zhang

jlzhang@ecust.edu.cn

1 State Key Laboratory of Photocatalysis on Energy and Environment, Fuzhou University, Fuzhou, China

2 Osaka Prefecture University, Osaka, Japan

3 Key Lab for Advanced Materials and School of Chemistry and Molecular Engineering, East China University of Science and Technology, Shanghai, China 
the most respected chemists in catalysis, he had always encouraged and inspired us. Although Prof. Che was also planning to contribute to this Special Issue, unfortunately, he passed away on August 7, 2019, due to illness. We would like to acknowledge his valuable support in the development and expansion of Res. Chem. Intermed. as well as his many great contributions to chemistry.

We pray for the peaceful repose of his soul.

September 24, 2019

Masakazu Anpo, Editor in Chief Jinlong Zhang, Editor

Publisher's Note Springer Nature remains neutral with regard to jurisdictional claims in published maps and institutional affiliations. 